\title{
The effect of asymmetrical accommodation on anisometropic amblyopia treatment outcomes
}

Article

Accepted Version

Creative Commons: Attribution-Noncommercial-No Derivative Works 4.0

Toor, S., Horwood, A. and Riddell, P. (2019) The effect of asymmetrical accommodation on anisometropic amblyopia treatment outcomes. Journal of AAPOS, 23 (4). 203.e1203.e5. ISSN 1091-8531 doi:

https://doi.org/10.1016/j.jaapos.2019.05.010 Available at https://centaur.reading.ac.uk/83772/

It is advisable to refer to the publisher's version if you intend to cite from the work. See Guidance on citing.

To link to this article DOI: http://dx.doi.org/10.1016/j.jaapos.2019.05.010

Publisher: Elsevier

All outputs in CentAUR are protected by Intellectual Property Rights law, including copyright law. Copyright and IPR is retained by the creators or other copyright holders. Terms and conditions for use of this material are defined in the End User Agreement.

www.reading.ac.uk/centaur 
Central Archive at the University of Reading

Reading's research outputs online 
The impact of asymmetrical accommodation on anisometropic amblyopia treatment outcomes

Sonia Toor, $\mathrm{PhD}^{1}$

Anna Horwood, $\mathrm{PhD}^{2,3}$

Patricia Riddell, DPhil ${ }^{2}$

1. Academic Unit of Ophthalmology and Orthoptics, University of Sheffield, UK

2. Infant Vision Laboratory, School of Psychology \& Clinical Language Sciences, University of Reading, UK

3. Orthoptic Department, Royal Berkshire Hospital, Reading, UK

Address for correspondence and reprints:

Dr Sonia Toor

Academic Unit of Ophthalmology and Orthoptics

Faculty of Medicine, Dentistry and Health

University of Sheffield

Beech Hill Road

Sheffield, S10 2RX, UK

sonia.toor@sheffield.ac.uk

Tel: (0114) 2159064

Word Count: 2,474

Abstract Word Count: 250

This research was supported by a UK Medical Research Council Clinical Scientist Fellowship awarded to AH (G0802809).

The study was conducted at the University of Reading.

No competing interests.

No financial disclosures. 


\section{ABSTRACT}

\section{Background:}

Previous research revealed that the majority of children with anisometropic amblyopia have asymmetrical accommodation. Only 19\% (5/26) had symmetrical accommodation, 58\% $(15 / 26)$ had aniso-accommodation and 23\% (6/26) had anti-accommodation. The aim of this preliminary study was to determine if the type of accommodation response was associated with a poor amblyopia treatment outcome in the same patients.

\section{Methods:}

The type of accommodation response of 26 children with anisometropic amblyopia was determined in a previous study. The final visual acuity (VA) in the amblyopic eye, post amblyopia treatment, was compared between those with symmetrical, aniso- and antiaccommodation.

\section{Results:}

There was a significant difference in final VA between the 3 accommodation groups $(\mathrm{p}=$ 0.023). The anisometropic amblyopes with anti-accommodation had the poorest final VA $(0.42 \pm 0.25( \pm 95 \% \mathrm{CI}) \log \mathrm{MAR})$ with a statistically significant difference when compared to those with aniso-accommodation $(0.14 \pm 0.08 \log \mathrm{MAR} ; \mathrm{p}=0.023)$. However the difference failed to reach significance when compared to those with symmetrical accommodation $(0.20$ $\pm 0.12 \log$ MAR; $p=0.234)$, probably due to the small sample size. The initial VA in the amblyopic eye and the degree of anisometropia were also significantly positively correlated with final VA (both $\mathrm{p}<0.001$ ).

\section{Conclusions:}


The presence of anti-accommodation in anisometropic amblyopia was associated with a poorer amblyopia treatment outcome. The initial VA in the amblyopic eye and the degree of anisometropia were also associated with a poorer treatment outcome. It is possible that all these factors are associated but further research is required to determine causal relationships.

\section{INTRODUCTION}

2 Accommodation is considered to be a symmetrical process with an equal accommodative

3 response in both eyes[1-5]. However, research within our laboratory has provided strong

4 evidence for the presence of asymmetrical accommodation in a group of hyperopic

5 anisometropic amblyopes[6, 7].

6 A larger prospective study, following a single case report[6], revealed that asymmetrical 7 accommodation was widespread in uncorrected hyperopic anisometropic amblyopia[7]. Only

$819 \%(5 / 26)$ of children with hyperopic anisometropia were found to have symmetrical 9 accommodation, whilst $81 \%(21 / 26)$ had asymmetrical accommodation to some extent. Of those, 58\% (15/26) demonstrated aniso-accommodation, where the amblyopic eye had lower accommodative gain, and 23\% (6/26) demonstrated "anti-accommodation", where the amblyopic eye accommodated more for distance than near.

The child with anti-accommodation in the initial case study had a poor response to amblyopia treatment with a final VA in the amblyopic eye of $0.35 \log$ MAR[6]. The success rate of anisometropic amblyopia treatment varies between 47-95\%. Although the degree of anisometropia, initial VA and the depth of amblyopia have been implicated, there is no general consensus on the factors that predict treatment success[8]. The poor response to treatment of the child in the case study suggested to us that anti-accommodation could be an additional factor that could indicate the likelihood of a poor outcome to amblyopia treatment. 
The main aim of this preliminary study was to determine whether the type of accommodation response, in particular, the presence of anti-accommodation, was associated with a poor amblyopia treatment outcome.

\section{MATERIALS AND METHODS}

The study adhered to the Declaration of Helsinki, obtained University and UK National Health Service Ethics Committee approval, and obtained fully informed consent from parents and age-appropriate assent from children.

Twenty-six children aged between 4 and 8 years were recruited from a local hospital with a primary diagnosis of hyperopic anisometropic amblyopia. They were assessed using cycloplegic retinoscopy and a fundus and media check and full correction was given. They completed an orthoptic investigation, which included VA testing using the Keeler (Keeler Ltd, Windsor, UK) or Sonksen (Haag-Streit, Essex, UK) crowded LogMAR tests. All participants had VA in the non-amblyopic/sound eye of at least $0.2 \log$ MAR (6/9.5), with $>0.1 \log$ MAR interocular difference. All had worn their spectacles for at least six weeks and had undergone occlusion therapy, if this had been required, by the time of data collection. Occlusion therapy was stopped after three consecutive visits of stable vision and this was taken to be the final VA. The final VA of the amblyopic eye was extracted from the hospital case notes during the laboratory study[7]. Successful treatment was defined as a final VA in the amblyopic eye of $0.20 \log$ MAR (6/9.5) or better. Other extracted information included the presenting initial VA of the amblyopic eye, the degree of anisometropia (difference in spherical equivalent) and the presence/absence of a microtropia, as these were considered to be potential confounding variables. In our previous report on this group[7], accommodation had been assessed over a range of distances, simultaneously in both eyes, using a Plusoptix S04 photorefractor in PowerRef II 
mode. Data was collected after spectacles had been worn for six weeks but at varying time points during occlusion therapy. The mean accommodative gain of the sound eye was 0.86 \pm 0.08 ( $\pm 95 \%$ confidence interval $(\mathrm{CI})$ ) and the mean accommodative gain of the amblyopic eye was $0.41( \pm 0.22)$. The $95 \%$ CI for the accommodation gain in the sound eye $( \pm 0.08$; equivalent to $0.25 \mathrm{D}$ difference in accommodation between the eyes at $0.33 \mathrm{~m}$ ) was used as a comparative value to define each individual's accommodative response. The study revealed three types of accommodation response and the participants were grouped based on these responses:

- $19 \%$ symmetrical accommodation $(n=5 / 26)$ : the accommodative gain in the amblyopic eye was within the $95 \%$ CI of the mean gain of the sound eye. The amblyopic eye had a similar lag of accommodation to the sound eye at near and in the distance.

- $58 \%$ aniso-accommodation $(\mathrm{n}=15 / 26)$ : asymmetrical accommodation, as the accommodative gain in the amblyopic eye was greater than the upper boundary of the $95 \% \mathrm{CI}$ of the mean gain of the sound eye. The accommodative gain was greater in the sound eye due to the amblyopic eye under-accommodating.

- $23 \%$ anti-accommodation $(n=6 / 26)$ : asymmetrical accommodation, as the accommodative gain in the amblyopic eye was again greater than the upper boundary of the $95 \% \mathrm{CI}$ of the mean gain of the sound eye. The sound eye accommodated more at near than in the distance but the amblyopic eye accommodated more in the distance than at near (negative accommodative gain in the amblyopic eye).

The final VA of the amblyopic eye was compared between the three groups with SPSS v 24 software using a univariate analysis (final VA as the dependent variable and group as the fixed factor). Further ANOVA analyses and Pearson correlations included the initial VA and the degree of anisometropia. Post hoc t-tests were run as required and used Bonferroni 
correction. Where assumptions of sphericity are violated, the Greenhouse-Geisser statistics

70 are quoted.

\section{RESULTS}

Across all 3 groups, the mean final VA in the amblyopic eye, post treatment, was $0.21 \pm 0.09$ $( \pm 95 \%$ CI $) \log$ MAR (6/9.5; range -0.10 to $1.00 \log$ MAR $)$. The initial VA in the amblyopic eye was $0.68 \pm 0.12 \log$ MAR (6/30; range 0.275 to $1.75 \log$ MAR). The degree of anisometropia was $3.03 \pm 0.40 \mathrm{D}$ (range 1.75 to $5.75 \mathrm{D}$ ).

Overall, 7 (27\%) anisometropic amblyopes had no microtropia, 6 (23\%) had a microtropia without identity (minimal manifest deviation of less than 10 prism dioptres base out observable on cover test) and $9(35 \%)$ had a microtropia with identity (no movement seen on cover test and central suppression, diagnosed using the 4 prism dioptre test or assessment of fixation ). The remaining $4(15 \%)$ patients had no record of investigation of a microtropia with identity within their case notes.

\section{Final VA}

Fifteen $(58 \%)$ of the anisometropic amblyopes had a successful treatment outcome (VA of $0.2 \log$ MAR or better in the amblyopic eye). Eight (31\%) had a successful outcome following refractive adaptation alone, with all these patients in the symmetrical or anisoaccommodation group.

There was a significant difference in final VA between the 3 accommodation groups $(F(2,23)$ $=4.31, \mathrm{p}=0.026)($ Figure 1$)$. The anti-accommodation group had a mean final VA of 0.42 $\pm 0.25 \log$ MAR and a significantly worse visual outcome compared to the anisoaccommodation group $(0.14 \pm 0.08 \log$ MAR, $\mathrm{p}=0.023$; mean difference of $0.28 \operatorname{logMAR}$ with $95 \%$ CI $0.03-0.54)$. Although the difference in final VA in the anti-accommodation group failed to reach significance when compared to the symmetrical accommodation group 
93

94

95

96

97

98

99

100

101

102

103

104

105

106

107

108

109

110

111

112

113

114

115

$(0.20 \pm 0.12 \log$ MAR, $\mathrm{p}=0.234 ;$ mean difference of $0.22 \log \mathrm{MAR}$ with $95 \% \mathrm{CI}-0.09-0.54)$ the small participant numbers in both of these groups suggest the analysis could be underpowered. There was no significant difference between the symmetrical and anisoaccommodation groups $(\mathrm{p}=1.00$; mean difference of $0.06 \log \mathrm{MAR}$ with $95 \% \mathrm{CI}-0.21-$ $0.33)$.

\section{Initial VA}

The initial VA and final VA had a strong positive correlation $(r=0.65,95 \%$ CI $0.35-0.83, p$ $<0.001$ ), so a worse initial VA correlated with a worse final VA. On comparison of the 3 accommodation groups, the anti-accommodation group had a worse initial VA (antiaccommodation: $0.92 \pm 0.34 \log \mathrm{MAR}$; aniso-accommodation: $0.62 \pm 0.13 \log \mathrm{MAR}$; symmetrical accommodation: $0.58 \pm 0.17 \log$ MAR) but this difference failed to reach significance $(F(2,23)=2.55, \mathrm{p}=0.100)$. The data were re-analysed to compare the improvement from initial to final VA (symmetrical accommodation: $0.39 \pm 0.25 \log$ MAR; aniso-accommodation: $0.49 \pm 0.13 \log \mathrm{MAR}$; anti-accommodation: $0.50 \pm 0.13 \log \mathrm{MAR}$ ) but there was no significant difference between the groups $(\mathrm{F}(2,23)=0.379, \mathrm{p}=0.690)$ (Figure 2).

\section{Degree of anisometropia}

In terms of the degree of anisometropia, there was a strong positive correlation with the initial VA $(r=0.64,95 \%$ CI $0.34-0.82, p<0.001)$ and the final VA $(r=0.57,95 \%$ CI $0.23-0.78 p$ $=0.002)$. There was a significant difference on comparison of the 3 groups $(F(2,23)=15.38$, $\mathrm{p}<0.001)$. The anti-accommodation group $(4.42 \pm 0.76 \mathrm{D})$ had a significantly greater degree of anisometropia in comparison to the symmetrical accommodation group $(2.85 \pm 0.55 \mathrm{D} ; \mathrm{p}=$ $0.004)$ and aniso-accommodation group $(2.53 \pm 0.32 \mathrm{D} ; \mathrm{p}<0.001)$. There was no significant 
difference in the degree of anisometropia between the symmetrical and aniso-accommodation

117 groups $(\mathrm{p}=1.00)$

118 Microtropia

119 The final VA in those with no microtropia, microtropia with identity and microtropia without identity was $0.11( \pm 0.08) \log$ MAR, $0.28( \pm 0.20) \log$ MAR and $0.33( \pm 0.15) \log$ MAR respectively. There was no significant difference in the final VA between these groups $(\mathrm{F}(2,19)=1.592, \mathrm{p}=0.230)$.

Two anisometropes in the symmetrical accommodation group, 3 in the aniso-accommodation group and 4 in the anti-accommodation group had a microtropia with identity. One anisometrope in the symmetrical accommodation group, 3 in the aniso-accommodation group and 2 in the anti-accommodation group had a microtropia without identity. Due to the small number of microtropes in each group, any analysis to determine if this is a potential confounding variable would be inconclusive but it is interesting to note that both types of microtropia were present in all groups.

\section{DISCUSSION}

This preliminary study revealed that the presence of anti-accommodation in anisometropic amblyopes was associated with a poorer amblyopia treatment outcome. A greater degree of anisometropia and possibly a poorer initial VA were also associated with a poorer visual outcome.

The anisometropic amblyopia treatment success rate of $58 \%$ falls within the range of 47 to 95\% cited in previous literature[9-14]. Similar to results of previous studies[15, 16], 31\% of patients resolved their amblyopia through refractive treatment alone. All of these children had symmetrical or aniso-accommodation. None had anti-accommodation. 
The anisometropic amblyopes with anti-accommodation had a significantly worse final VA than those with aniso-accommodation (0.42 logMAR vs $0.14 \log$ MAR). Those with antiaccommodation had a worse final VA compared to those with symmetrical accommodation (0.42 logMAR vs $0.20 \log$ MAR) but this did not reach significance, likely due to the low patient numbers in both these groups. We suggest that this association between antiaccommodation and a poor treatment outcome could either be a sign of a more severe primary defect or because poorer accommodation for near hinders treatment.

In our previous report on this group, accommodation had also been assessed with spectacles[7]. There was no evidence of optical over-correction in the anti-accommodation group in the distance where VA is tested. At a distance of $2 \mathrm{~m}$, where $0.5 \mathrm{D}$ of accommodation should be exerted, only a mean of $0.044 \mathrm{D}$ over-accommodation had occurred. However, in the anti-accommodation group we have evidence of possible overcorrection in the distance under other viewing conditions (mean of $0.27 \mathrm{D}$ ) which might impact on the VA assessment.

Potential confounding variables were investigated. As found in previous literature[9-11, 1720], a worse initial VA was associated with a worse final VA, but regardless of accommodation type. Previous studies have also found a positive relationship between the degree of anisometropia and the final VA[12, 17, 18]. Those with anti-accommodation had a significantly higher degree of anisometropia. Therefore, although the presence of antiaccommodation was associated with a worse final VA, there could be an association between these two factors, the initial VA and the degree of anisometropia but causal relationships cannot be resolved due to low participant numbers. The majority of researchers support the finding that anisometropia causes amblyopia[11, 17, 21-23] so a greater degree of anisometropia results in a worse initial VA. One possible theory is that the presence of anti- 
accommodation is associated with a larger degree of anisometropia and hence a worse initial VA, and in turn a worse final VA.

An important question is how these data might transfer to clinical practice. Although this is yet to be studied, it might be possible to determine the presence of anti-accommodation in patients by conducting dynamic retinoscopy at near and distance with both eyes open, and comparing it to the anisometropia found on cycloplegic refraction. In aniso-accommodation, there will be different amounts of anisometropia between the two distances, with a greater degree of anisometropia at near, and in the case of anti-accommodation, less anisometropia in the distance compared to the cycloplegic refraction.

The presence of anti-accommodation means that more accommodation occurs in the distance, and could result in the full cycloplegic refraction overcorrecting the hypermetropia. However, with spectacles these patients no longer demonstrated anti-accommodation, although they still demonstrated some milder aniso-accommodation[7]. Even if accurate dynamic retinoscopy is not possible to reveal subtle differences in anisometropia, we suggest that every child returning for VA assessment with their first pair of glasses should have their VA tested with a pinhole or small minus lens to check that the tested vision is not affected by a small overcorrection for distance.

The findings from this research might enable clinicians to predict which children might have poorer treatment outcomes in anisometropic amblyopia. As anti-accommodation was associated with a worse treatment outcome, it could be argued that occlusion therapy could be started sooner. None of these patients had a successful outcome following refractive treatment alone, so it is a topic for further study whether refractive adaptation is of benefit in those with anti-accommodation or whether patching should be started immediately. 
Interestingly, the child from the initial case study[6] learned to accommodate symmetrically

187

188

after five years of full correction and continuing monocular activity encouraged by her parents (after prescribed occlusion had been stopped 4 years earlier). On the other hand we have seen cases of persisting anti-accommodation in adults. Future research will be aimed at determining whether those with anti-accommodation can be taught to accommodate symmetrically and whether this consequently improves amblyopia treatment outcomes.

This was a preliminary laboratory based study limited by the small sample size. Sufficient participants were not available to perform an adjusted statistical analysis and therefore it was not possible to separate the effects of final VA and type of accommodation response from the effects of initial VA and the degree of anisometropia. Each accommodation group might have differed before treatment had started. In addition, instead of a full assessment conducted at the time of testing, information regarding the participants was extracted from the hospital notes. Although this was necessary for some information, such as the initial VA, this prevented a full diagnosis in some cases. Fifteen percent of patients had no recorded assessment for the presence of a microtropia with identity. Those diagnosed with a microtropia with identity did not all have the presence of eccentric fixation confirmed using the visuoscope. Further research is required to address these confounding variables in relation to the found association between the presence of anti-accommodation and a poor amblyopia treatment outcome.

\section{CONCLUSIONS}

The presence of anti-accommodation in hyperopic anisometropic amblyopia was associated with a poorer treatment outcome. The initial VA and degree of anisometropia were also associated with a worse response to amblyopia treatment. It is possible that all these factors are associated but further research is required to determine causal relationships. 
Fellowship awarded to AH (G0802809).

213

214

215

216

217

218

219

220

221

222

223

224

225

226

227

228

229

230

231

232

233

234

235

236

237

238

239

240

241

242

243

244

245

246

247

248

249

250

251

252

\section{REFERENCES}

1. Koh, L.H. and W.N. Charman, Accommodative responses to anisoaccommodative targets. Ophthalmic Physiol Opt, 1998. 18(3): p. 254-62.

2. Bharadwaj, S.R. and T.R. Candy, The effect of lens-induced anisometropia on accommodation and vergence during human visual development. Invest Ophthalmol Vis Sci, 2011. 52(6): p. 3595-603.

3. Flitcroft, D.I., S.J. Judge, and J.W. Morley, Binocular interactions in accommodation control: effects of anisometropic stimuli. J Neurosci, 1992. 12(1): p. 188-203.

4. Ball, E.A., A study of consensual accommodation. Am J Optom Arch Am Acad Optom, 1952. 29(11): p. 561-74.

5. Campbell, F.W., Correlation of accommodation between the two eyes. J Opt Soc Am, 1960. 50: p. 738.

6. Horwood, A.M. and P.M. Riddell, Independent and reciprocal accommodation in anisometropic amblyopia. Journal of American Association for Pediatric Ophthalmology and Strabismus, 2010. 14(5): p. 447-449.

7. Toor, S., A.M. Horwood, and P. Riddell, Asymmetrical accommodation in hyperopic anisometropic amblyopia. Br J Ophthalmol, 2018. 102(6): p. 772-778.

8. Toor, S.S., A.M. Horwood, and P.M. Riddell, Anisometropic amblyopia: Factors influencing the success or failure of its treatment. British and Irish Orthoptic Journal, 2012. 9: p. 9-16.

9. Flynn, J.T., et al., The therapy of amblyopia: an analysis of the results of amblyopia therapy utilizing the pooled data of published studies. Transactions of the American Ophthalmology Society, 1998. 96: p. 431-453.

10. Flynn, J.T., et al., The therapy of amblyopia: an analysis comparing the results of amblyopia therapy utilizing two pooled data sets. Transactions of the American Ophthalmology Society, 1999. 97: p. 373-395.

11. Hussein, M.A.W., et al., Risk factors for treatment failure of anisometropic amblyopia. Journal of American Association for Pediatric Ophthalmology and Strabismus, 2004. 8(5): p. 429-434.

12. Scott, W.E., et al., Amblyopia Treatment Outcomes. Journal of American Association for Pediatric Ophthalmology and Strabismus, 2005. 9(2): p. 107-111.

13. De Vries, J., Anisometropia in children: analysis of a hospital population. British Journal of Ophthalmology, 1985. 69: p. 504-507.

14. PEDIG, A randomized trial of atropine vs. patching for treatment of moderate amblyopia in children. Arch Ophthalmol, 2002. 120(3): p. 268-78.

15. Stewart, C.E., et al., Refractive adaptation in amblyopia: quantification of effect and implications for practice. British Journal of Ophthalmology, 2004. 88: p. 1552-1556.

16. PEDIG, Treatment of anisometropic amblyopia in children with refractive correction. Ophthalmology, 2006. 113(6): p. 895-903.

17. Cobb, C.J., et al., Factors influencing visual outcome in anisometropic amblyopes. British Journal of Ophthalmology, 2002. 86: p. 1278-1281. 
Figure 2. The change from initial (circles) to final (squares) visual acuity for each participant

18. Chen, P.-L., et al., Anisometropic Amblyopia Treated with Spectacle Correction Alone: Possible Factors Predicting Success and Time to Start Patching. American Journal of Ophthalmology, 2007. 143(1): p. 54-60.

19. Kutschke, P.J., W.E. Scott, and R.V. Keech, Anisometropic amblyopia. Ophthalmology, 1991. 98(2): p. 258-63.

20. Woodruff, G., et al., Factors affecting the outcome of children treated for amblyopia. Eye (London, England), 1994. 8 ( Pt 6): p. 627-31.

21. Wu, C. and D.G. Hunter, Amblyopia: Diagnostic and Therapeutic Options. American Journal of Ophthalmology, 2006. 141(1): p. 175-184.e2.

22. Weakley, D.R., The association between anisometropia, amblyopia, and binocularity in the absence of strabismus. Transactions of the American Ophthalmology Society, 1999. 97: p. 987-1021.

23. Fielder, A.R. and M.J. Moseley, Anisometropia and amblyopia - chicken or egg? British Journal of Ophthalmology, 1996. 80: p. 857-858.

\section{LEGENDS}

Figure 1. Mean final visual acuity $( \pm 95 \% \mathrm{CI})$ in each group following treatment.

271 in each group. 